\title{
Influence of TNF- $\alpha$ inhibition on oxidative stress of rheumatoid arthritis patients
}

\author{
F. Cacciapaglia ${ }^{1}$, M.G. Anelli², D. Rizzo ${ }^{3}$, E. Morelli ${ }^{3}$, C. Scioscia ${ }^{2}$, D. Mazzotta', \\ F. lannone ${ }^{2}$, G. Lapadula ${ }^{2}$ \\ ${ }^{1}$ Internal Medicine Unit and Rheumatology Clinic, N. Melli Hospital, \\ San Pietro Vernotico (BR), Italy; ${ }^{2}$ Interdisciplinary Department of Medicine, Rheumatology Unit, Medical \\ School, University of Bari, Italy; ${ }^{3}$ Morelli \& Di Pierro Lab, Squinzano (LE), Italy
}

\begin{abstract}
SUMMARY
The aim of this study was to assess circulating levels of reactive oxygen metabolites (ROMs) as a marker of oxidative stress in rheumatoid arthritis (RA) patients during an anti-tumor necrosis factor alpha (TNF- $\alpha$ ) treatment.

We enrolled 40 patients with RA ( 36 females; age $53 \pm 13$ yrs) treated with different subcutaneously administered TNF- $\alpha$ inhibitors. The oxidative status was determined on the basis of plasma samples taken before, at 24 and 52 weeks of the anti-TNF- $\alpha$ treatment. Hydroperoxide levels were measured using the d-ROMs test, a useful clinically proven oxidative stress marker.

During the anti-TNF- $\alpha$ therapy, we observed a significant reduction in serum ROMs levels in RA patients from $33.2 \pm 10 \mathrm{mg} \mathrm{H} 2 \mathrm{O} 2 / \mathrm{L}$ at baseline to $29.5 \pm 7$ and $29.3 \pm 9 \mathrm{mg} \mathrm{H} 2 \mathrm{O} 2 / \mathrm{L}$, at 24 and 52 weeks, respectively ( $<<0.05$ ). We also identified a significant correlation between the oxidative stress status and the disease activity score on 28 joints/C-reactive protein and health assessment questionnaire disability index. The results of our study demonstrate that a good control of the disease with anti-TNF- $\alpha$ agents can reduce oxidative stress in RA patients. However, further studies of larger patient cohorts are needed to confirm these preliminary data.
\end{abstract}

Key words: Anti-TNF; oxidative stress; rheumatoid arthritis; reactive oxygen species.

Reumatismo, 2015; 67 (3): 97-102

\section{INTRODUCTION}

$\mathrm{R}$ heumatoid arthritis (RA) is a chronic, systemic inflammatory disease that affects primarily the joints with synovial hyperplasia and may result in structural joint damage and disability (1). The combination of genetic susceptibility along with various environmental factors is reported to play a critical role in the pathogenesis of this disease and leads to persistent immune system activation and highly complex and coordinated processes that initiate and perpetuate an autoimmune response with a low-grade chronic inflammation (2).

Reactive oxygen species (ROS) are chemically reactive molecules containing oxygen generated during normal oxygen metabolism, which play important roles in cell signaling and homeostasis. However, an imbalance between the systemic produc- tion of ROS and the biological system's ability to readily detoxify these metabolites results in oxidative stress in cells with an ensuing damage to their components, such as proteins, lipids, and DNA (3).

ROS have been classically described as harmful products released during inflammatory diseases that can activate and perpetuate the immune response (4). In several autoimmune diseases, pro-inflammatory compounds (cytokines and prostaglandins) together with ROS are released at sites of inflammation. In particular, the overproduction of tumor necrosis factor alpha (TNF- $\alpha$ ) is thought to be the main contributor to increased ROS release in patients with RA (5). Therefore, high ROS levels have proven to be related to disease activity (6).

The aim of this study was to assess the effect of an anti-TNF- $\alpha$ treatment on circu- $\overline{\text { Corresponding author: }}$

Fabio Cacciapaglia

U.O.C. di Medicina Interna Ambulatorio di Reumatologia

Ospedale N. Melli

Via Lecce, 246 - 72027 San Pietro V.co (BR)

E-mail: f.cacciapaglia@unicampus.it 
lating levels of reactive oxygen metabolites (ROMs) and oxidative stress in patients with active RA.

\section{PATIENTS AND METHODS}

According to the 2010 classification criteria of the American College of Rheumatology/European League Against Rheumatism (ACR/EULAR) (7), we consecutively enrolled 40 early RA patients, who failed treatment with disease modifying antirheumatic drugs (DMARDs) and were eligible for a biologic therapy, in compliance with the recommendations of the Italian
Society of Rheumatology (8). All patients were evaluated for disease activity by the disease activity score on 28 joints/C-reactive protein (DAS28-CRP), functional status by the health assessment questionnaire disability index (HAQ-DI), and were screened for latent tuberculosis, B and C hepatitis as well as human immunodeficiency virus and varicella zoster virus exposure/infection, and history of previous malignancies. Smokers of more than 10 cigarettes/day were excluded. The clinical features of the enrolled patients are reported in Table I. Corticosteroids (CCS) and/ or DMARDs treatment at baseline were

Table I - Clinical features of rheumatoid arthritis patients (N. 40).

\begin{tabular}{|c|c|c|c|}
\hline & Baseline & 24 weeks & 52 weeks \\
\hline Female, n. (\%) & $36(90 \%)$ & & \\
\hline Age, years - mean $\pm S D$ & $53 \pm 13$ & & \\
\hline Disease duration, months - mean \pm SD & $6.8 \pm 3.7$ & & \\
\hline RF positive, n. (\%) & $31(77.5)$ & & \\
\hline ACPA positive, n. (\%) & $29(72.5)$ & & \\
\hline $\begin{array}{l}\text { Treatment, n. (\%) } \\
\text { CCS } \\
\text { CCS+MTX } \\
\text { CCS+LFM } \\
\text { CCS+SSZ }\end{array}$ & $\begin{array}{l}3(75) \\
27(67.5) \\
4(10.0) \\
6(15.0)\end{array}$ & & \\
\hline $\begin{array}{l}\text { Anti-TNF } \\
\text { Etanercept } \\
\text { Adalimumab } \\
\text { Golimumab }\end{array}$ & $\begin{array}{l}15(37.5 \%) \\
17(42.5 \%) \\
8(20 \%)\end{array}$ & & \\
\hline $\mathrm{ESR}, \mathrm{mm} / \mathrm{h}-$ mean $\pm \mathrm{SD}$ & $57 \pm 27$ & $22 \pm 21^{*}$ & $18 \pm 15^{\star}$ \\
\hline $\mathrm{CRP}, \mathrm{mg} / \mathrm{L}-$ mean $\pm \mathrm{SD}$ & $6.4 \pm 3.7$ & $2.1 \pm 1.4^{*}$ & $1.3 \pm 1.2^{*}$ \\
\hline $\mathrm{DAS} 28-\mathrm{CRP}-$ mean $\pm \mathrm{SD}$ & $6.4 \pm 0.9$ & $3.5 \pm 1.2^{*}$ & $3.3 \pm 1.1^{*}$ \\
\hline $\begin{array}{l}\text { EULAR response: none/moderate/good - n. (\%) } \\
\text { [DAS28 improvement }<0.6 / 0.6-1.2 />1.2]\end{array}$ & - & $\begin{array}{l}4 / 14 / 22^{\star \star} \\
(10 / 35 / 55)\end{array}$ & $\begin{array}{l}0 / 9 / 27^{* *} \\
(0 / 25 / 75)\end{array}$ \\
\hline $\mathrm{HAQ}-\mathrm{DI}-$ mean $\pm \mathrm{SD}$ & $1.8 \pm 0.7$ & $0.9 \pm 0.4^{*}$ & $0.7 \pm 0.5^{*}$ \\
\hline ROS serum levels - mean $\pm \mathrm{SD}\left(\mathrm{mgH}_{2} \mathrm{O}_{2} / \mathrm{L}\right)$ & $33.2 \pm 10$ & $29.5 \pm 7^{*}$ & $29.3 \pm 9^{*}$ \\
\hline $\begin{array}{l}\text { Oxidative stress: low/moderate/high - } \mathrm{n} \text {. (\%) } \\
\left.\text { [ROS levels }<27 / 27-32 />32 \mathrm{mgH}_{2} \mathrm{O}_{2} / \mathrm{L}\right]\end{array}$ & $\begin{array}{l}0 / 17 / 23 \\
(0 / 43 / 57)\end{array}$ & $\begin{array}{l}20 / 16 / 4^{\star \star} \\
(50 / 40 / 10)\end{array}$ & $\begin{array}{l}28 / 8 / 0^{\star \star} \\
(78 / 22 / 0)\end{array}$ \\
\hline
\end{tabular}

SD, standard deviation; RF, rheumatoid factor; ACPA, anti-citrullinated peptide antibodies; CCS, corticosteroids; MTX, methotrexate; LFM, luflunomide; SSZ, sulfasalazine; TNF, tumor necrosis factor; ESR, erythrosedimentation rate; CRP, C-reactive protein; DAS28, disease activity score on 28 joints; EULAR, European League Against Rheumatism; HAQ-DI, health assessment questionnaire disability index; ROS, reactive oxygen species. ${ }^{*} \mathrm{p}<0.05 ;{ }^{* *} \mathrm{p}<0.001$. 
maintained in combination with TNF- $\alpha$ inhibitors and dosages remained unchanged during the study. At baseline and after 24 and 52 weeks from the initiation of treatment with anti-TNF- $\alpha$ drugs for all patients, the four-variable DAS28-CRP was measured and blood samples were taken and frozen at $-80^{\circ} \mathrm{C}$ until laboratory assessment. Plasma levels of ROMs were measured by performing the Diacron reactive oxygen metabolite d-ROM test, according to the manufacturer's instructions. This test reflects the amount of organic hydroperoxides that is related to the free radicals from which they are formed. When the samples are dissolved in an acidic buffer, the hydroperoxides react with the transition metal (mainly iron) ions released from the proteins in the acidic medium and are converted to alkoxy and peroxy radicals. These newly-formed radicals oxidize an additive aromatic amine (N, N-diethyl-para-phenylen-diamine) and cause the formation of a relatively stable colored cation radical that is spectrophotometrically detectable at 505 $\mathrm{nm}$. The results are expressed in arbitrary units (U. Carr) with one unit corresponding to $0.8 \mathrm{mg} / \mathrm{L}$ of hydrogen peroxide. According to manufacturer's indications and previous preclinical and clinical studies (9, 10), ROS levels $>32 \mathrm{mg} \mathrm{H} 2 \mathrm{O} 2 / \mathrm{L}$ are considered indicative of high oxidative stress; values between 27 and $32 \mathrm{mg} \mathrm{H} 2 \mathrm{O} 2 / \mathrm{L}$ correspond to a moderate oxidative stress, while ROS serum levels < $27 \mathrm{mg} \mathrm{H} 2 \mathrm{O} 2 / \mathrm{L}$ indicate a low oxidative stress.

Data are expressed as the mean \pm 1 standard deviation and analyzed using the Prism statistical package (GraphpadInstat, version $3)$. Continuous variables were evaluated by using the one-way analysis of variance followed by paired t tests, while categorical data were calculated using the Fisher's exact probability test or $\chi 2$-test, when appropriate. $\mathrm{P}$ values $<0.05$ were considered statistically significant.

\section{RESULTS}

At baseline all patients had a high disease activity (mean DAS28-CRP $=6.4 \pm 0.9$ ) and during the treatment we observed a significant improvement in DAS28 both after 24 weeks $(3.5 \pm 1.2)$ and 52 weeks $(3.3 \pm 1.1) \quad(\mathrm{p}<0.001)$. After 24 weeks of treatment, 22 patients reached a good response, 14 patients had a moderate re-

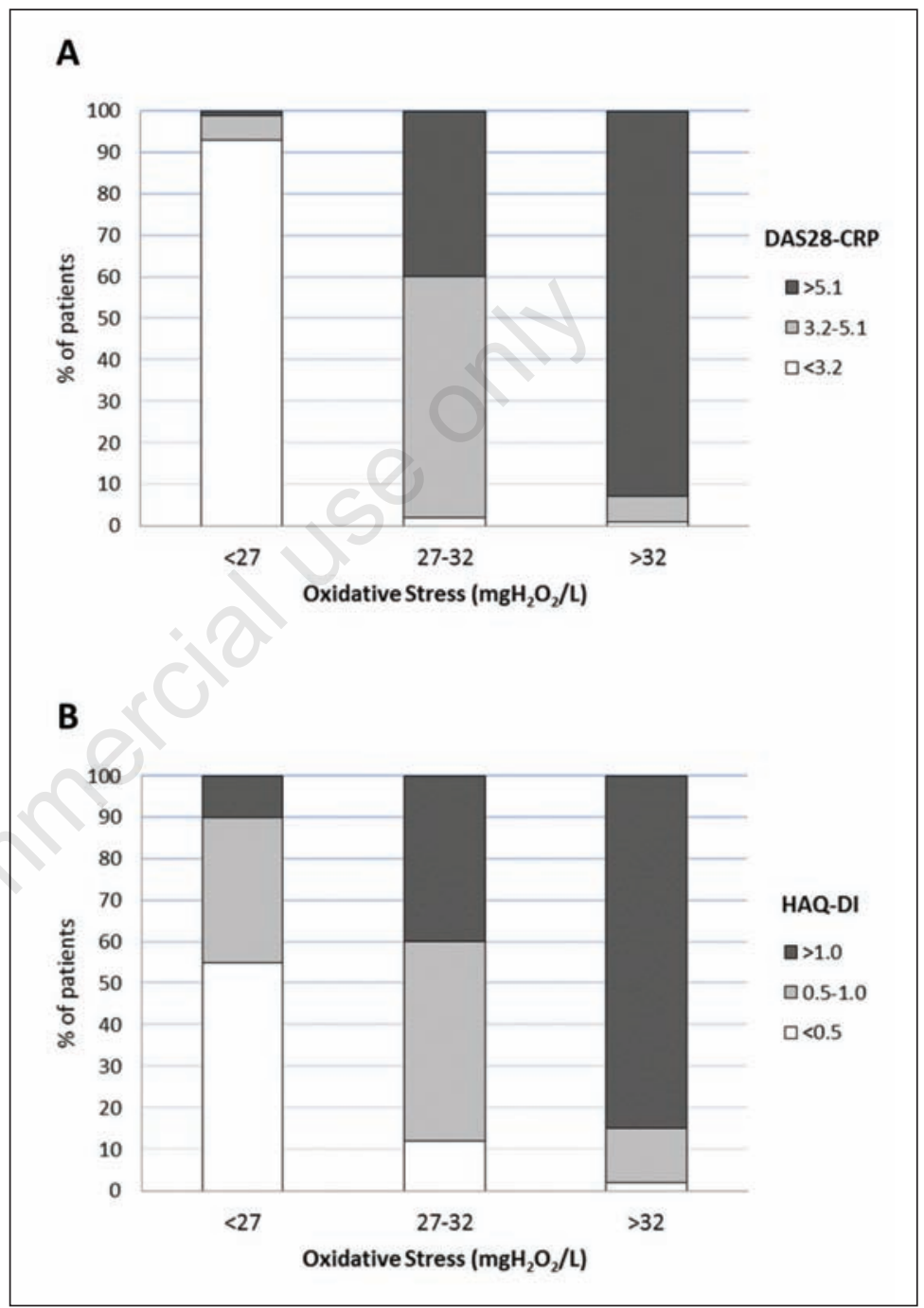

Figure 1 - Association of oxidative stress in rheumatoid arthritis patients with disease activity (A) and disability (B). Oxidative stress evaluated by reactive oxygen species serum levels: high >32 mg H2O2/L; moderate 2732 mg H2O2/L; low <27 mg H2O2/L. Disease activity according to disease activity score on 28 joints/C-reactive protein (DAS28CRP): high >5.1, moderate 3.2-5.1; low $<3.2$. Disability assessed by health assessment questionnaire disability index (HAQ-DI): high $>1.0$, moderate 0.5-1.0; low $<0.5$. A) $\chi 2=247$; $p<0.001$; B) $\chi 2=138 ; p<0.001$. 
sponse and 4 patients had no response according to the EULAR definitions. The last 4 patients dropped out from the study and were switched to other treatments. After 52 weeks, 5 more patients reported a good EULAR response. The HAQ significantly decreased from $1.8 \pm 0.7$ at baseline to $0.9 \pm 0.4$ and $0.7 \pm 0.5$ after 24 and 52 weeks of treatment, respectively $(\mathrm{p}<0.001)$.

As to the ROS serum levels of RA patients, at baseline we observed a mean ROS of $33.2 \pm 10 \mathrm{mg} \mathrm{H} 2 \mathrm{O} 2 / \mathrm{L}$, with a high oxidative stress in 23 patients ( $>32 \mathrm{mg} \mathrm{H} 2 \mathrm{O} 2 / \mathrm{L}$ ), and a moderate oxidative stress in 17 patients ( ROS $<32$ and $>27 \mathrm{mg} \mathrm{H} 2 \mathrm{O} 2 / \mathrm{L}$ ).

After 24 weeks of anti-TNF $\alpha$ treatment, the mean ROS serum levels dropped to $29.5 \pm 7 \mathrm{mg} \mathrm{H} 2 \mathrm{O} 2 / \mathrm{L}$ ( $\mathrm{p}=0.02$ vs baseline). The 20 patients who reached a low disease activity (DAS28-CRP $<3.2$ ) had a low oxidative stress status ( $\mathrm{ROS}<27 \mathrm{mg} \mathrm{H} 2 \mathrm{O} 2 / \mathrm{L}$ ), while the 4 patients who had no EULAR response had a high oxidative stress (ROS $>32 \mathrm{mg} \mathrm{H} 2 \mathrm{O} 2 / \mathrm{L}$ ).

After 52 weeks of treatment, ROS serum levels were $29.3 \pm 9 \mathrm{mg} \mathrm{H} 2 \mathrm{O} 2 / \mathrm{L}(\mathrm{p}=0.02$ vs basal), 26 out of 36 patients $(72 \%)$ had a low disease activity (DAS28-CRP $<3.2$ ) and a low oxidative stress status (ROS $<27$ mg H2O2/L).

Lastly, we also observed a significant association between the oxidative stress evaluated by measuring the circulating ROS serum levels and the disease activity according to DAS28-CRP $(\chi 2=247$; $\mathrm{p}<0.001)$ and the functional status of RA patients assessed by the HAQ-DI $(\chi 2=138$; p<0.001) (Fig. 1).

\section{DISCUSSION AND CONCLUSIONS}

Our study confirmed the correlation between circulating ROS levels and disease activity in RA patients. However, the mechanisms responsible for the onset of RA remain unclear. Smoking is considered to be one of the most important extrinsic risk factors with a role in its development and severity (11). Recent studies demonstrated the interrelation between smoke, oxidative stress, inflammation, autoanti- body formation and epigenetic changes in RA (12). ROS play a significant role in the progressive joint destruction both upstream and downstream to the nuclear factor kappa B (NF- $\mathrm{B}$ ) and TNF- $\alpha$ pathways, which are located at the center of the inflammatory response (13). Moreover, the increased oxidative stress is actually considered the main key driver in RA extrajoint morbidity, mainly in accelerated atherosclerosis, which may led to increased cardiovascular disease and mortality. The immune response, via cytokines and chemokines that attract monocytes, plays a role in these alterations ranging from the formation and stabilization of the atherosclerotic plaque to its progression and rupture (14). The control of the systemic inflammation is a therapeutic goal which not only translates in the remission of musculoskeletal symptoms, but also in an improvement of the patient overall health. Recent biologic immunosuppressive therapies targeting pro-inflammatory cytokines proved to be able to control disease activity and halt the progressive joint destruction (15). TNF- $\alpha$ inhibitors exert an antioxidative stress activity interfering with the pleiotropic effect of this cytokine. TNF- $\alpha$ stimulates $\mathrm{NAD}(\mathrm{P}) \mathrm{H}$ oxidases activity and increases intracellular hydrogen peroxide. The up-regulation of TNF- $\alpha$ impairs NO bioavailability and contributes to the development of mitochondrial oxidative stress (16). Lastly, the activation of the Caspase cascade induced by TNF- $\alpha$ demonstrated to promote endothelial apoptotic cell death which, along with increased oxidative stress and vascular inflammation, increases the cardiovascular risk (17). The beneficial action of anti-TNF- $\alpha$ drugs on endothelial cells seems to be ascribable to their excellent anti-inflammatory properties (18), yet their metabolic and cardiovascular effects are still unclear. In the early 2000s, some trials with anti-TNF- $\alpha$ raised some concern about its cardiovascular safety, worsening previous heart failure, while the anti-interleukin 6 treatment demonstrated to modify the lipid pattern by creating an atherogenic profile. On the other hand, data from $\mathrm{Na}$ tional registries of RA patients seem to 
demonstrate a reduction in cardiovascular events in responders to the biological treatment (19). High levels of ROS are associated with obesity, cardiovascular diseases and atherosclerosis. Only few studies investigated the effects of TNF- $\alpha$ blocking therapy on the oxidative stress. In accordance with Biniecka et al. (20) and Kageyama et al. (21), we observed that TNF $\alpha$ antagonism is able to reduce oxidative stress in responders. A lack of effective control of the disease activity with CCS and DMARDs results in a state of high inflammation and concurrent high circulating levels of ROS. On the contrary, the addition of anti-TNF- $\alpha$ agents led to a good disease control and consequent reduction of ROS levels and oxidative stress.

Our demonstration of a reduction in circulating ROS levels during an anti-TNF- $\alpha$ treatment, subcutaneously administered in combination with CCS and/or DMARDs, may explain the ability of these agents to reduce cardiovascular morbidity and mortality in RA patients who achieve a good disease control.

Previous studies highlighted the potential role of increased lipid peroxidation and decreased enzymic and non-enzymic antioxidants in RA, suggesting a very important role of oxidative stress in the pathogenesis of the disease. A previous study by Jacobson et al. (22) failed to demonstrate a correlation between plasma glutathione peroxidase concentrations and the severity of the disease measured using the HAQ-DI. To our knowledge, this is the first study that observed a significant correlation between the oxidative stress evaluated by the dROM-test and the severity of the HAQ-DI. RA patients with more severe symptoms of pain and joint inflammation at disease onset have an increased risk of falling in the most disabled group of patients later, with a direct relationship between joint and systemic inflammation and loss of functional ability (23). The early management of systemic and joint inflammation with an effective treatment, as observed in good responders, and above all the resulting improvement in tender and swollen joints count of the composite indices of disease activity lead to a good control of pain and function with better outcomes. Therefore, the improvement of oxidative stress observed in the patients achieving the DAS28-CRP low disease activity might also have an impact on the degree of disability with an improvement in HAQ-DI. In conclusion, the inhibition of TNF- $\alpha$ is able to control the disease activity and reduce the oxidative stress and has a positive impact on the disability of RA patients. This finding may explain the systemic effects of anti-TNF- $\alpha$ agents and justify the initiation of an early treatment to prevent the extra-articular manifestations of the disease (i.e., cardiovascular comorbidity). As a whole, in patients with RA, the correlation between DAS28-CRP and ROS levels suggests that the measurement of oxidative stress may serve as a biomarker to monitor disease severity in RA.

\section{Key messages}

- Rheumatoid arthritis patients with active disease have high oxidative stress.

- Good disease control with TNF- $\alpha$ inhibitors can reduce oxidative stress. Oxidative stress correlates with DAS28CRP and HAQ-DI.

Conflict of interest: the authors declare no conflict of interest.

\section{REFERENCES}

1. Majithia V, Geraci SA. Rheumatoid arthritis: diagnosis and management. Am J Med. 2007; 120: 936-9.

2. Perricone C, Ceccarelli F, Valesini G. An overview on the geneticof rheumatoid arthritis: a never-ending story. Autoimmun Rev. 2011; 10: 599-608.

3. Valko M, Leibfritz D, Moncol J, Cronin MT, Mazur M, Telser J. Free radicals and antioxidants in normal physiological functions and human disease. Int J Biochem Cell Biol. 2007; 39: 44-84.

4. Hotamisligil GS. Inflammation and metabolic disorders. Nature. 2006; 4 44: 860-7.

5. García-González A, Gaxiola-Robles R, Zenteno-Savín T. Oxidative stress in patients with rheumatoid arthritis. Rev Invest Clin. 2015; 67: 46-53.

6. Datta S, Kundu S, Ghosh P, De S, Ghosh A, Chatterjee M. Correlation of oxidant status 
with oxidative tissue damage in patients with rheumatoid arthritis. Clin Rheumatol. 2014; 33: 1557-64.

7. Aletaha D, Neogi T, Silman AJ, Funovits J, Felson DT, Bingham CO 3rd, et al. 2010 Rheumatoid arthritis classification criteria: an American College of Rheumatology/European League Against Rheumatism collaborative initiative. Arthritis Rheum. 2010; 62: 2569-81.

8. Caporali R, Conti F, Alivernini S, Atzeni F, Seriolo B, Cutolo M, et al. Recommendations for the use of biologic therapy in rheumatoid arthritis: update from the Italian Society for Rheumatology I. Efficacy. Clin Exp Rheumatol. 2011; 29: S7-14.

9. Cornelli U, Terranova R, Luca S, Cornelli M, Alberti A. Bioavailability and antioxidant activity of some food supplements in men and women using the D-Roms test as a marker of oxidative stress. J Nutr. 2001; 131: 3208-11.

10. Pasquini A, Luchetti E, Marchetti V, Cardini G, Iorio EL. Analytical performances of d-ROMs test and BAP test in canine plasma. Definition of the normal range in healthy Labrador dogs. Vet Res Commun. 2008; 32: 137-43.

11. Söderlin MK, Andersson M, Bergman S; BARFOT study group. Second-hand exposure to tobacco smoke and its effect on disease activity in Swedish rheumatoid arthritis patients. Data from BARFOT, a multicenter study of RA. Clin Exp Rheumatol. 2013; 31: 122-4.

12. Costenbader KH, Gay S, Alarcón-Riquelme ME, Iaccarino L, Doria A. Genes, epigenetic regulation and environmental factors: which is the most relevant in developing autoimmune diseases? Autoimmun Rev. 2012; 11: 604-9.

13. Kaminska B. MAPK signaling pathways as molecular targets for anti-inflammatory therapy from molecular mechanisms to therapeutic benefits. Biochim Biophys Acta. 2005; 1754 : 253-2.

14. Hansson GK, Libby P, Schönbeck U, Yan ZQ. Innate and adaptive immunity in the pathogenesis of atherosclerosis. Circ Res. 2002; 91 : 281-91.

15. Bizzi E, Massafra U, Laganà $B$, Bruzzese V, Diamanti AP, Cassol M, et al. Radiological outcomes in randomized controlled trials on biologic therapies for rheumatoid arthritis: a narrative review. Clin Rheumatol. 2014; 33 : 877-84.

16. Ungvari Z, Gupte SA, Recchia FA, Batkai S, Pacher P. Role of oxidative-nitrosative stress and downstream pathways in various forms of cardiomyopathy and heart failure. Curr Vasc Pharmacol. 2005; 3: 221-9.

17. Manna SK, Mukhopadhyay A, Aggarwal BB. Resveratrol suppresses TNF-induced activation of nuclear transcription factors NF-kappa $\mathrm{B}$, activator protein-1, and apoptosis: potential role of reactive oxygen intermediates and lipid peroxidation. J Immunol. 2000; 164: 650919.

18. Branen L, Hovgaard L, Nitulescu M, Bengtsson E, Nilsson J, Jovinge S. Inhibition of tumor necrosis factor-alpha reduces atherosclerosis in apolipoprotein E knockout mice. Arterioscler Thromb Vasc Biol. 2004; 24: 2137-42.

19. Cacciapaglia F, Navarini L, Menna P, Salvatorelli E, Minotti G, Afeltra A. Cardiovascular safety of anti-TNF-alpha therapies: facts and unsettled issues. Autoimmun Rev. 2011; 10: 631-5.

20. Biniecka M, Kennedy A, Ng CT, Chang TC, Balogh E, Fox E, et al. Successful tumour necrosis factor (TNF) blocking therapy suppresses oxidative stress and hypoxia-induced mitochondrial mutagenesis in inflammatory arthritis. Arthritis Res Ther. 2011; 13: R121.

21. Kageyama Y, Takahashi M, Ichikawa T, Torikai E, Nagano A. Reduction of oxidative stress marker levels by anti-TNF- $\alpha$ antibody, infliximab, in patients with rheumatoid arthritis. Clin Exp Rheumatol. 2008; 26: 73-80.

22. Jacobson GA, Ives SJ, Narkowicz C, Jones G. Plasma glutathione peroxidase (GSH-Px) concentration is elevated in rheumatoid arthritis: a case-control study. Clin Rheumatol. 2012; 31 : 1543-7.

23. Cohen JD, Dougados M, Goupille P, Cantagrel A, Meyer O, Sibilia J, et al. Health assessment questionnaire score is the best predictor of 5 year quality of life in early rheumatoid arthritis. J Rheumatol. 2006; 33: 1936-41. 